\title{
PROJETO AERODESIGN: FERRAMENTA PARA DESENVOLVIMENTO DE HABILIDADES DOS ALUNOS E ESTREITAMENTO DA UNIVERSIDADE COM A COMUNIDADE
}

DOI: $10.37702 / 2175-957 X . C O B E N G E .2021 .3402$

Ana Paula Mattos - anapmattos@ufpa.br

Universidade Federal do Pará UFPA

Travessa 14 Abril 1489

66063-005 - Belém - PA

José Augusto Pinheiro Quitério Junior - augustopinheirojr97@gmail.com

Universidade Federal do Pará

Jardim Jader Barbalho 103

67033-897 - Ananindeua - PA

Andrey Coelho das Neves - andreycoelho143@gmail.com UFPA

Rua A 28

66670-030 - Belém - PA

Leonardo Costa Tavares - tavaresleonardo15@gmail.com Universidade Federal do Pará

Travessa são Francisco 122

66023-530 - Belém - PA

Vinicius Silva dos Reis - vinicius.reis@itec.ufpa.br

Universidade Federal do Pará

Passagem jardim Brasília 06

67020-000 - Ananindeua - PA

Suanny Quemel Mesquita - suanny.mesquita@itec.ufpa.br Universidade Federal do Pará

Rua Siqueira Mendes 1143

66810-050 - Belém - PA

RAFAEL ÁVILA MORAES - rafael_moraes30@hotmail.com

UNIVERSIDADE FEDERAL DO PARÁ

Conjunto Guajará 1 WE 621362 
67143-380 - Ananindeua - PA

Resumo: A Equipe Uirapuru Aerodesign é um projeto de extensão da UFPA, criado pelos alunos de graduação em Engenharia Mecânica. Os quais possuem interesse em projetos multidisciplinares e, atualmente, na equipe há membros da engenharia mecânica e elétrica. No projeto, aplica-se os conhecimentos nas áreas de modelagem numérica, elementos finitos, desenho técnico, aerodinâmica, resistência dos materiais, seleção de materiais, mecatrônica, análise de desempenho e projeto estrutural. O objetivo da equipe é a elaboração e a execução do projeto de aeronaves para participar de competições nacionais, aperfeiçoando e desenvolvendo habilidades importantes para um engenheiro. $O$ intuito do projeto é ampliar os conhecimentos dos alunos além da sala de aula, integração entre a universidade e a comunidade e outras instituições. $O$ projeto desenvolve também diversas habilidades importantes para o crescimento profissional, tais como elaboração de seminários, projetos, orçamentos e trabalho em grupo. Este artigo visa apresentar como projetos de extensão e pesquisa conciliados intensificam o crescimento pessoal, profissional dos alunos e ao mesmo tempo trazem a comunidade para mais perto da universidade. Durante $o$ projeto observou-se o crescimento dos membros, o aperfeiçoamento de habilidades e o interesse de todos em realizar atividades voltadas também para a comunidade. Devido ao atual cenário, estas atividades e a preparação de material foram realizadas de maneira online. Os objetivos foram alcançados pelo projeto, conseguindo desenvolver o projeto do avião e ao mesmo tempo levando conhecimento à comunidade por meio do YouTube com uma média de 250 visualizações nos vídeos e participação de membros externos nos minicursos.

Palavras-chave: Aerodesign. Projeto Multidisciplinar. Engenharia. 


\section{INTRODUÇÃO}

As Universidades federais indiretamente favorecem toda a população pela formação de profissionais, produção de novas informações e ações de extensão, mas seus benefícios diretos são apropriados por poucos. As atividades de Extensão, que seriam um momento de interação dessas instituições com a Sociedade e que poderiam ampliar o alcance das suas ações, ainda são tratadas como de menor importância frente às outras atividades universitárias de ensino e pesquisa, restringindo ainda mais os benefícios da Universidade percebidos socialmente (RAMIREZ, 2017).

A Extensão Universitária tem um importante papel a cumprir na integração dos avanços gerados na Universidade com a sociedade em geral. Essas ações têm ainda um grande potencial de divulgação científica, uma vez que podem levar a informação científica de uma forma facilmente assimilável para toda a população. Mas para que isso aconteça, a extensão tem que se comportar como um setor inovador no organismo universitário (RAMIREZ, 2017).

Segundo Mendonça (2002), afirmam que poucos são os que têm acesso direto aos conhecimentos gerados na universidade pública e que a extensão universitária é imprescindível para a democratização do acesso a esses conhecimentos, assim como para o redimensionamento da função social da própria universidade, principalmente se for pública. A extensão universitária possibilita a formação do profissional cidadão e se credencia, cada vez mais, junto à sociedade como espaço privilegiado de produção do conhecimento significativo para a superação das desigualdades sociais existentes.

Mediante este contexto, projetos que conciliam o desenvolvimento tecnológico e sua divulgação são de extrema importância. A Equipe Uirapuru Aerodesign surge com a intenção de promover minicursos, palestras e seminários para toda universidade e comunidade. Além de elaborar artigos, desenvolver bancadas experimentais e formar uma equipe apta a participar das competições SAE Brasil Aerodesign, e SAE International Aerodesign, respectivamente, as principais competições acadêmicas da área no Brasil e no mundo. Desta maneira os alunos participantes da Equipe Uirapuru Aerodesign terão mais oportunidade de colocar em prática habilidades importantes da engenharia, tais como: o desenvolvimento de projetos mecânicos, a Análise Estrutural, a Análise Computacional da Dinâmica dos Fluidos, Cálculo Numérico, dentre outras, bem como de se capacitar para realizar pós-graduação na área e, futuramente, contribuir para desenvolver essa importante subárea das engenharias. Ao mesmo tempo que estarão interagindo de maneira ativa os alunos da rede pública de ensino fundamental, médio e técnico ao projeto, aproximando mais a realidade da universidade para a comunidade. Equipes de aerodesign são importantes pois estimulam o desenvolvimento de habilidades técnicas e interpessoais importantes, há pelo menos 20 universidades no Brasil que possuem projeto de aerodesign.

A Sociedade de Engenheiros de Mobilidade (SAE) tem como objetivo propiciar a difusão e o intercâmbio de técnicas e conhecimentos de Engenharia Aeronáutica. A SAE international organiza desde 1986 a competição SAE Aerodesign, em que os participantes têm a oportunidade de se envolver com um caso real de desenvolvimento de projeto aeronáutico, desde sua a concepção, projeto detalhado, construção e testes (SAE 2018; ITA 2019). 
Em 1999, a SAE BRASIL organizou a versão nacional da competição, e desde então apresenta substantiva melhora na qualidade dos projetos apresentados. As equipes participantes são desafiadas a se adequar a regulamentos, os quais se tornam mais complexos a cada ano. Estes se baseiam em desafios reais enfrentados pela indústria aeronáutica. As avaliações e classificação das equipes são realizadas por engenheiros da indústria aeronáutica, com base na concepção e desempenho dos projetos desenvolvidos.

Os participantes, por meio da competição, encontram oportunidade de conhecer os princípios básicos da aviação, e desenvolver habilidades úteis para qualquer ramo profissional da engenharia que vierem a ingressar, como aprender a trabalhar em equipe, pesquisar, planejar e trabalhar para atingir objetivos necessários para o desenvolvimento do projeto (VERAS 2014, EDER 2017).

O projeto Aerodesign está contemplado no Plano Pedagógico do Curso, o qual tem como objetivo fomentar a participação dos discentes de engenharia em competições nacionais que estimulam novos conhecimentos e aprendizados, além de propor aos discentes o contato e interação com outras instituições de ensino superior, trocando conhecimentos e experiências.

O projeto expande os conhecimentos adquiridos em sala de aula, por se tratar de um projeto multidisciplinar, como ocorre em um processo real de desenvolvimento de um produto na indústria. Dessa maneira, os alunos adquirem experiência no desenvolvimento de um produto de engenharia. O qual consiste desde a captação de recursos, planejamento de gastos, escolha das melhores soluções, aprender a trabalhar para atender datas e cronogramas, utilização de softwares de engenharia para desenho e simulação, utilização de ferramentas e processos de fabricação, desenvolvimento e execução do projeto, melhorando a qualidade de formação do discente, que passará a ter uma visão mais ampla e sistêmica dos processos que ocorrem em escala industrial.

A equipe deve desenvolver um projeto aeronáutico de um avião rádio controlado, desde a concepção e o projeto detalhado, até a construção, seguindo o regulamento da competição.

As equipes são desafiadas com regulamentos baseados em desafios reais enfrentados pela indústria aeronáutica. A competição SAE Brasil Aerodesign possui três categorias: Regular, Advanced e Micro, com requisitos específicos para cada classe. A Equipe Uirapuru desenvolveu o projeto categoria Micro para o torneio principal e para o Torneio de acesso de 2020.

$\mathrm{Na}$ concepção do projeto aeronáutico, é fundamental que a equipe realize uma análise detalhada de desempenho em todas as fases de voo. De acordo com o regulamento (SAE, 2020).

Desta maneira este artigo visa apresentar como a Equipe Uirapuru concilia projeto de pesquisa e extensão em um só projeto, motivando os alunos da universidade e complementando o curso e suas habilidades.

\section{METODOLOGIA}

O projeto Uirapuru realiza o projeto de pesquisa e a integração da comunidade (extensão) comitantemente durante o projeto. Será descrito brevemente como é realizado estas etapas. 


\subsection{Projeto da aeronave}

A metodologia para a obtenção da aeronave consiste em organizar a equipe em subgrupos responsáveis por sistemas específicos do projeto e a união dessas subequipes em um projeto de integração. De posse de projetos realizados em edições passadas da competição, a equipe definirá um novo modelo de aeronave, que tenha as características estruturais, de sustentação e manobrabilidade necessárias para atender às especificações solicitadas pela organização da competição. Nesta fase, os conceitos aprendidos em sala serão estendidos para a aplicação prática.

Disciplinas específicas como motores, mecânica dos fluidos, aerodinâmica, dinâmica de voo, estruturas, elementos de máquinas, vibrações mecânicas, controle e automação de sistemas, resistência e seleção dos materiais, entre outros conhecimentos que devem ser aprofundados pela equipe para projetar uma aeronave que obedeça às regras da competição com o melhor custo/benefício.

O projeto e execução de um aeromodelo é um processo que envolve a integração de diversas equipes responsáveis por uma disciplina da Engenharia Aeronáutica, de maneira interativa e interdisciplinar, de forma que os dados de saída em uma etapa de uma subequipem são utilizados como entradas para uma etapa de outra subequipe, com fins a elaborar o projeto e relatório da aeronave. Cada equipe é formada por um líder de equipe e demais membros, sendo ambos discentes dos cursos de engenharia da UFPA, e todos os membros participam em conjunto das etapas de montagem. Atualmente a equipe é formada por 8 subequipes: desempenho, cargas, aeroelasticidade, estruturas, aerodinâmica, estabilidade e controle, elétrica e marketing. Um dos membros é escolhido para estudar pilotagem e exercer essa função durante a competição SAE BRASIL AERODESIGN, caso a equipe não possua nenhum membro para ser o piloto a competição disponibiliza um piloto para a prova. A Figura 1 apresenta as subequipes e os principais objetivos de cada subequipe.

Figura 1 - Subequipes e objetivos do projeto.

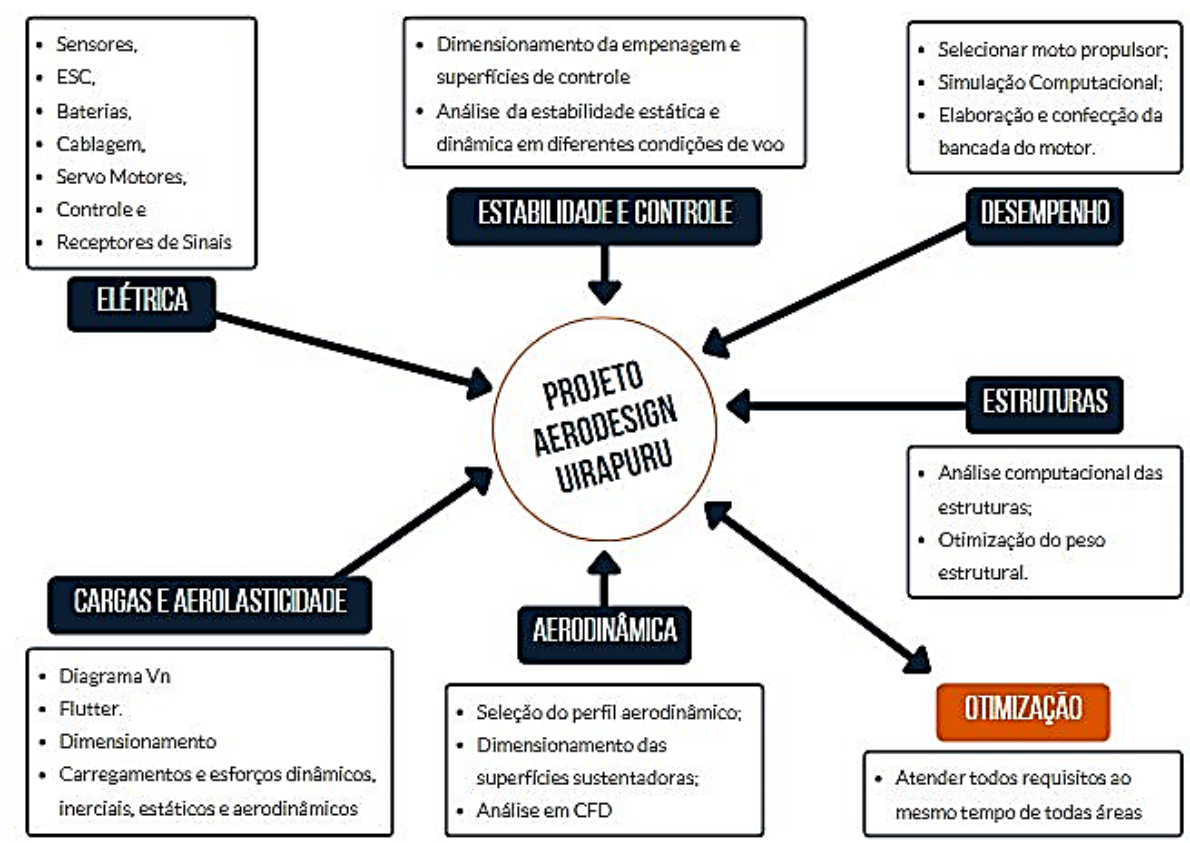

Fonte: Autor. 
O projeto é divido em três etapas: conceitual, preliminar e detalhado para todas as subequipes, a fim de delimitar com mais acuidade as decisões tomadas e as condições de contorno. Estas etapas estão exemplificadas na Figura 2.

Figura 2 - Etapas do projeto da aeronave.

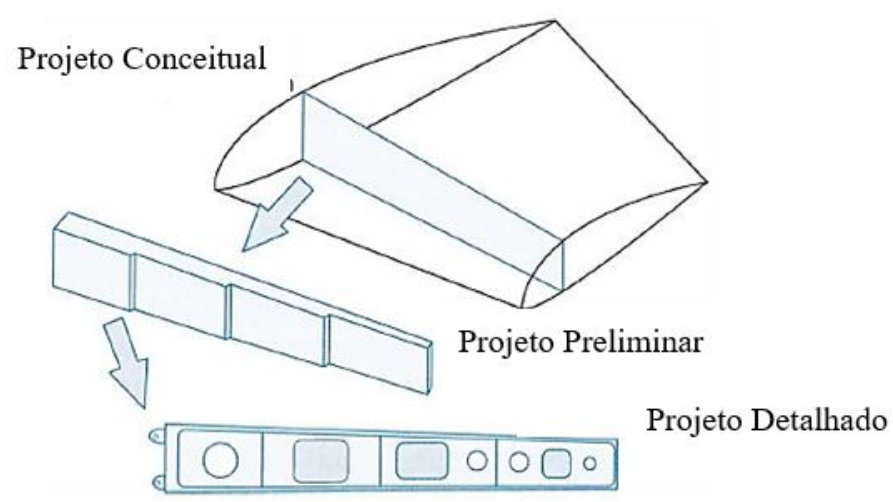

Fonte: Adaptado de ROSKAM 1985 e RAYMER 1992.

A Figura 3 apresenta um fluxograma do desenvolvimento do projeto do avião.

Figura 3 - Fluxograma do desenvolvimento do projeto.

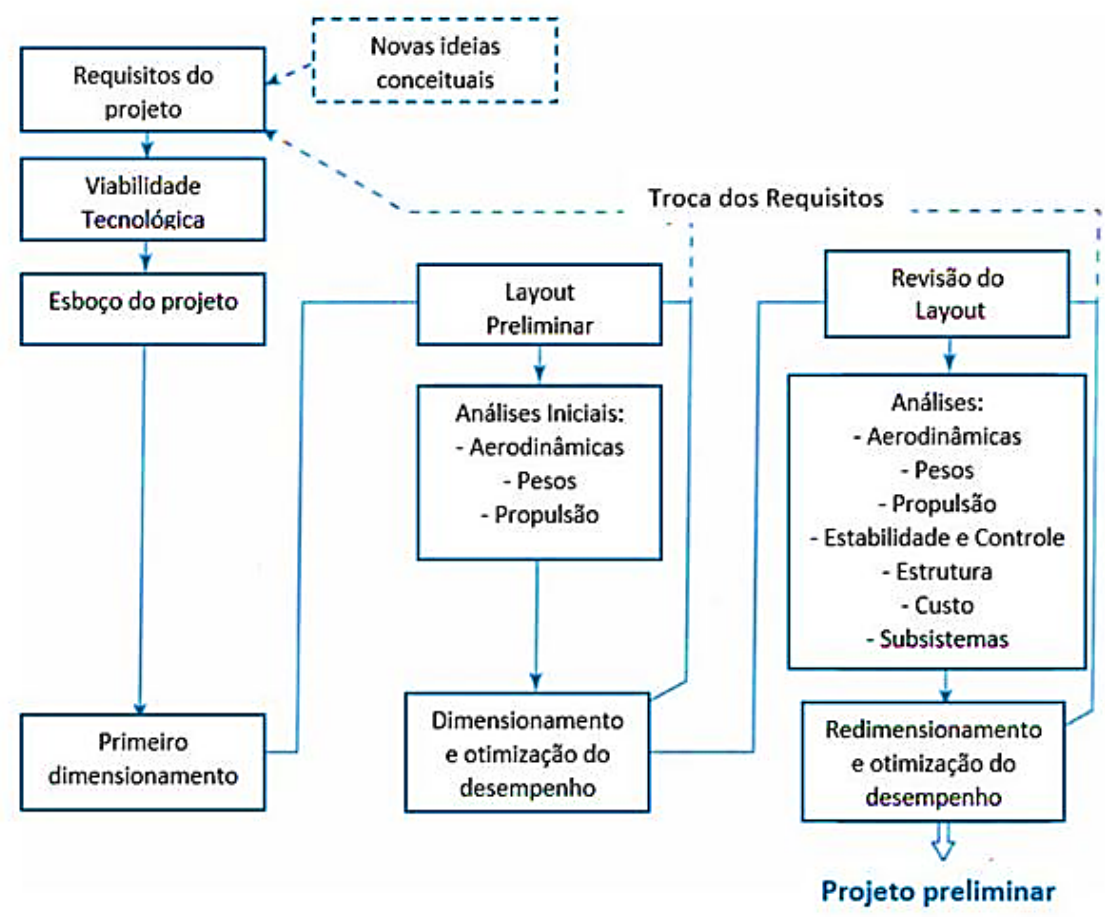

Fonte: Adaptado RAYMER 1992.

A fase prática envolve a seleção de materiais e construção física do primeiro protótipo. Nesta fase, os materiais e ferramentas serão adquiridos junto a parcerias e patrocínios, mediante um orçamento realizado pelos membros da equipe.

$\mathrm{Na}$ etapa seguinte, serão efetuados os testes para a competição. Esses testes se referem ao teste de potência do motor, resistência do trem de pouso, aerodinâmica, 
capacidade de carga, aceleração e capacidade de manobra. São testes extensivos, onde é posto à prova toda a capacidade de engenharia da equipe. A subequipe de desempenho projetou uma bancada para testar o motor, nesse projeto além de seleção de materiais, e design realizou-se análises estruturais dos componentes no software ANSYS WORKBENCH ${ }^{\circledR}$. A bancada está na fase inicial de sua construção e prevê-se sua finalização ainda no primeiro semestre de 2021. A subequipe de aerodinâmica atualmente está em fase de projeto de um túnel de vento didático, a fim de ajudar no projeto do avião, na parte experimental de aerodinâmica e ao mesmo tempo no minicurso que é oferecido para a comunidade e alunos da UFPA, desta maneira agregando valor ao curso de engenharia, os conhecimentos dos alunos que estão elaborando o projeto e dos alunos que terão contato com o experimento. Desta maneira podendo aplicar os conceitos vistos em sala de aula.

Após esses testes, são feitos os ajustes do projeto original corrigindo possíveis falhas e melhorando aspectos gerais do modelo. Finalmente, após a escrita do relatório e a confecção da versão final do avião é enviado um vídeo de voo para a comissão avaliadora da competição de acordo com o regulamento da SAE Brasil e posteriormente se aprovado a equipe participa da competição, que geralmente ocorre no mês de outubro em São José dos Campos.

\subsection{Atividades com a comunidade}

A equipe concilia as atividades de projeto da aeronave com as atividades relacionadas à integração com a comunidade e ao mesmo tempo aperfeiçoamento de habilidades dos integrantes além daquelas já desenvolvidas durante o projeto da aeronave. Tais como: trabalho em grupo, liderança, gestão do tempo, projeto e pessoas, aplicação da teoria em projeto real.

A integração com a comunidade acontece de diversas maneiras idealizadas pelo projeto, tais como: palestras, minicursos, publicações nas redes sociais, ida em feiras e escolas, elaboração de cartilhas educativas. No ano de 2020 e 2021 estas atividades estão sendo realizadas de maneira online devido a pandemia.

No ano de 2020 em janeiro a equipe participou da $1^{\text {a }}$ Expo Aero Estação, em Belém, onde apresentou seu avião e explicou o projeto (Figura 4).

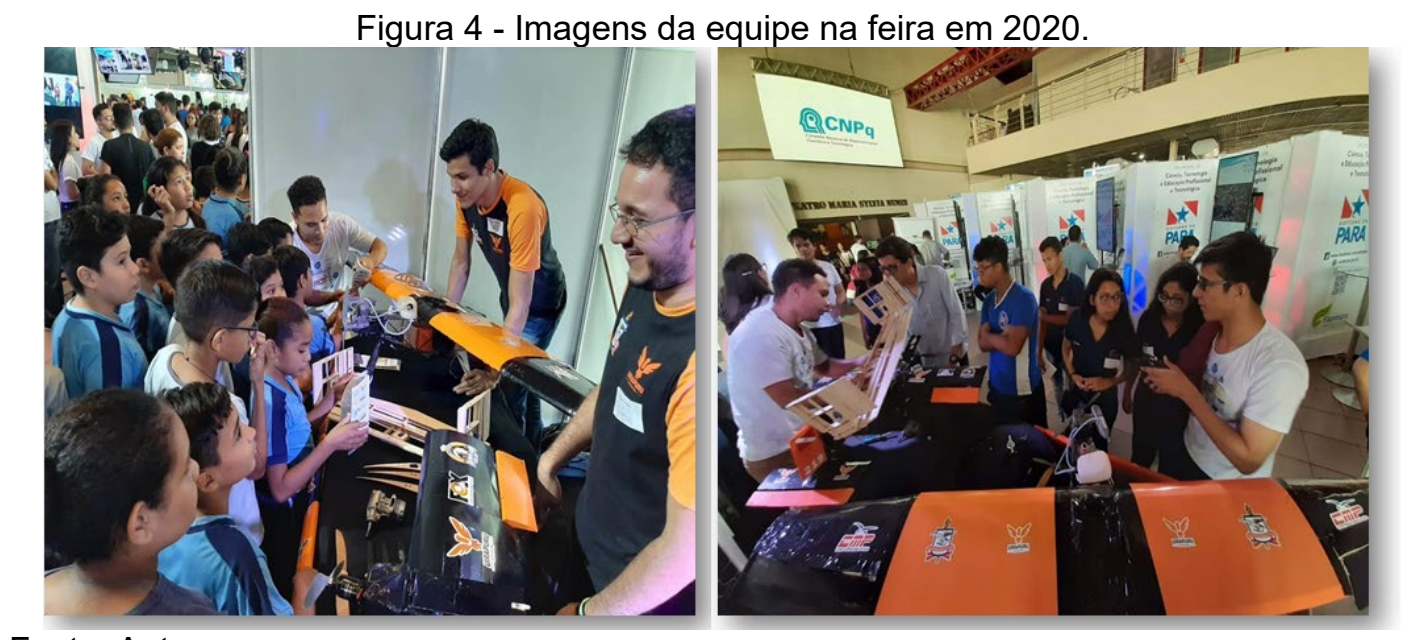

Fonte: Autor. 
O projeto visa ministrar ao menos dois minicursos de capacitação para os integrantes e os quais também são oferecidos para a comunidade. No ano de 2020 oferecemos os minicursos: Ansys ${ }^{\circledR}$ oferecido de maneira presencial com carga horária de 20 horas, em janeiro e de SolidWorks ${ }^{\circledR}$ de maneira online pelo canal da equipe. O minicurso de SolidWorks ${ }^{\circledR}$ ministrado por um aluno da engenharia mecânica, com carga horária de 12 horas, com 50 vagas, onde $30 \%$ era para comunidade. Os vídeos estão disponíveis no canal e atualmente possuem mais de 150 visualizações, desta maneira alcançando o objetivo de integração com a comunidade e disseminação de conhecimentos. Atualmente o projeto elabora dois minicursos, os quais serão online, um de aerodinâmica, o qual é uma idealização da subequipe de aerodinâmica, com 25 vagas, com uma carga horária de 15 horas. O segundo minicurso será de Matlab com carga horária de 20 horas o qual será ministrado por um colaborador da equipe da UNICAMP.

Durante o ano de 2020 realizou-se palestras temáticas: Desafio de um projeto de aerodesign; $O$ desafio de fazer parte de uma equipe de aerodesign e o que isso gera na vida dos integrantes; Da graduação ao mercado internacional; A importância da mecânica dos fluidos em um projeto de aeronave. Neste ano: Fundamentos e modelagem aerodinâmica em aeronaves de competição SAE-Aerodesign. Todas realizadas nas redes sociais da equipe, as quais tiveram um alcance de mais de 100 visualizações, portanto mostrando a cobertura que o projeto está conseguindo perante a universidade e a comunidade.

A função das palestras e minicursos é trazer mais pessoas para a universidade, e também, o conhecimento das atividades desenvolvidas, e ao mesmo tempo motivar os discentes que já estão no curso a continuar e se qualificar. Desta maneira, a equipe adquire habilidades importantes tanto para a carreira profissional quanto o amadurecimento pessoal, as quais são: conversação, organização, elaboração de material e criatividade. Neste propósito, o projeto visa realizar capacitação visando as necessidades dos membros. Realizou-se uma oficina de metodologia científica para os membros interessados na escrita de artigos científicos a fim de aprimorar a escrita e a utilização de ferramentas que auxiliam na elaboração de trabalhos científicos, tais como: Mendeley, Overleaf, sites de busca como Sciencedirect, Journal Finder, Google Acadêmico, dentre outros, é importante frisar que o projeto sempre almeja utilizar softwares livres. Durante o ano serão realizadas outras oficinas com finalidades diversas, como elaborar um currículo, como se comportar numa entrevista, elaboração de e-mail corporativos dentre outras.

No intuito de estreitar ainda mais o relacionamento entre a equipe e a comunidade, em especial alunos de escolas públicas, mesmo no atual cenário, este ano pretende-se realizar ao menos dois seminários online para apresentar a equipe, o projeto e mostrar o avião além de distribuir cartilhas educativas.

Realizou-se um questionário com membros e ex-membros da equipe, para identificar pontos fortes, além de identificar quais precisam ser melhorados. Ao todo, 29 pessoas responderam ao questionário elaborado, com as seguintes perguntas: se é membro ou exmembro; a permanência na equipe; o que a equipe mais agregou em suas vidas; motivo de saída da equipe; se indicaria o projeto para outros discentes; habilidades aprimoradas e desenvolvidas que o projeto lhe propiciou; e o que o projeto precisa melhorar. Este questionário servirá como ferramenta qualitativa para que o projeto cumpra os objetivos de construir o avião e ao mesmo tempo realize atividade que contribua e dissemine os conhecimentos com a comunidade de forma que estreite cada vez mais o relacionamento entre a comunidade e a universidade e contribuindo para o desenvolvimento desta. 


\section{Resultados e Conclusões}

No ano de 2020, durante a $22^{\circ}$ Competição SAE Brasil Aerodesign, a equipe conseguiu o $14^{\circ}$ lugar na competição (Tabela 1), uma das melhores colocações mesmo com adversidades advindas pela pandemia do COVID-19. Almejando-se a ampliação de contatos e disseminação de conhecimentos aplicados durante o projeto, a equipe visa a publicação de artigos, em 2021 a subequipe de aerodinâmica participou do XXVII CREEM, com o artigo: Dimensionamento da asa e desenvolvimento de um novo perfil para a competição SAE Brasil Aerodesign. Atualmente o resumo enviado pela subequipe de desempenho para o $26^{\circ} \mathrm{COBEM}$ foi aceito com o título: Design of a test bench for electric propulsion system of unmanned aerial vehicles.

Tabela 1 - Evolução da equipe Uirapuru na competição SAE.

\begin{tabular}{cccccc}
\hline Categoria & Ano & Edição & Posição & $\mathbf{N}^{\circ}$ & $\begin{array}{c}\text { Pontuação } \\
\text { total }\end{array}$ \\
\hline Micro & 2020 & $22^{\mathrm{a}}$ & $14^{\mathrm{a}}$ & 225 & 101,450 \\
Micro & 2018 & $20^{\mathrm{a}}$ & $22^{\mathrm{a}}$ & 219 & 19,940 \\
Micro & 2017 & $19^{\mathrm{a}}$ & Desistente & 220 & - \\
Micro & 2014 & $16^{\mathrm{a}}$ & $19^{\mathrm{a}}$ & 214 & 41,690 \\
Micro & 2013 & $15^{\mathrm{a}}$ & $20^{\mathrm{a}}$ & 223 & - \\
Regular & 2012 & $14^{\mathrm{a}}$ & $39^{\mathrm{a}}$ & 31 & 122,080 \\
Regular & 2011 & $13^{\mathrm{a}}$ & $53^{\mathrm{a}}$ & 76 & 83,720 \\
Regular & 2010 & $12^{\mathrm{a}}$ & 63 & 54 & 42,500 \\
Regular & 2009 & $11^{\mathrm{a}}$ & $3^{\mathrm{a}}$ & - & Desclassificado \\
Acesso & 2019 & $21^{\mathrm{a}}$ & $31^{\mathrm{a}}$ & - & 4,802 \\
Acesso & 2017 & $19^{\mathrm{a}}$ & $19^{\mathrm{a}}$ & - & 5,800 \\
\hline
\end{tabular}

Fonte: Autor.

A Figura 5 apresenta o avião projetado pela equipe em 2020. 
Figura 5 - Vista explodida do projeto do avião da Série Micro.
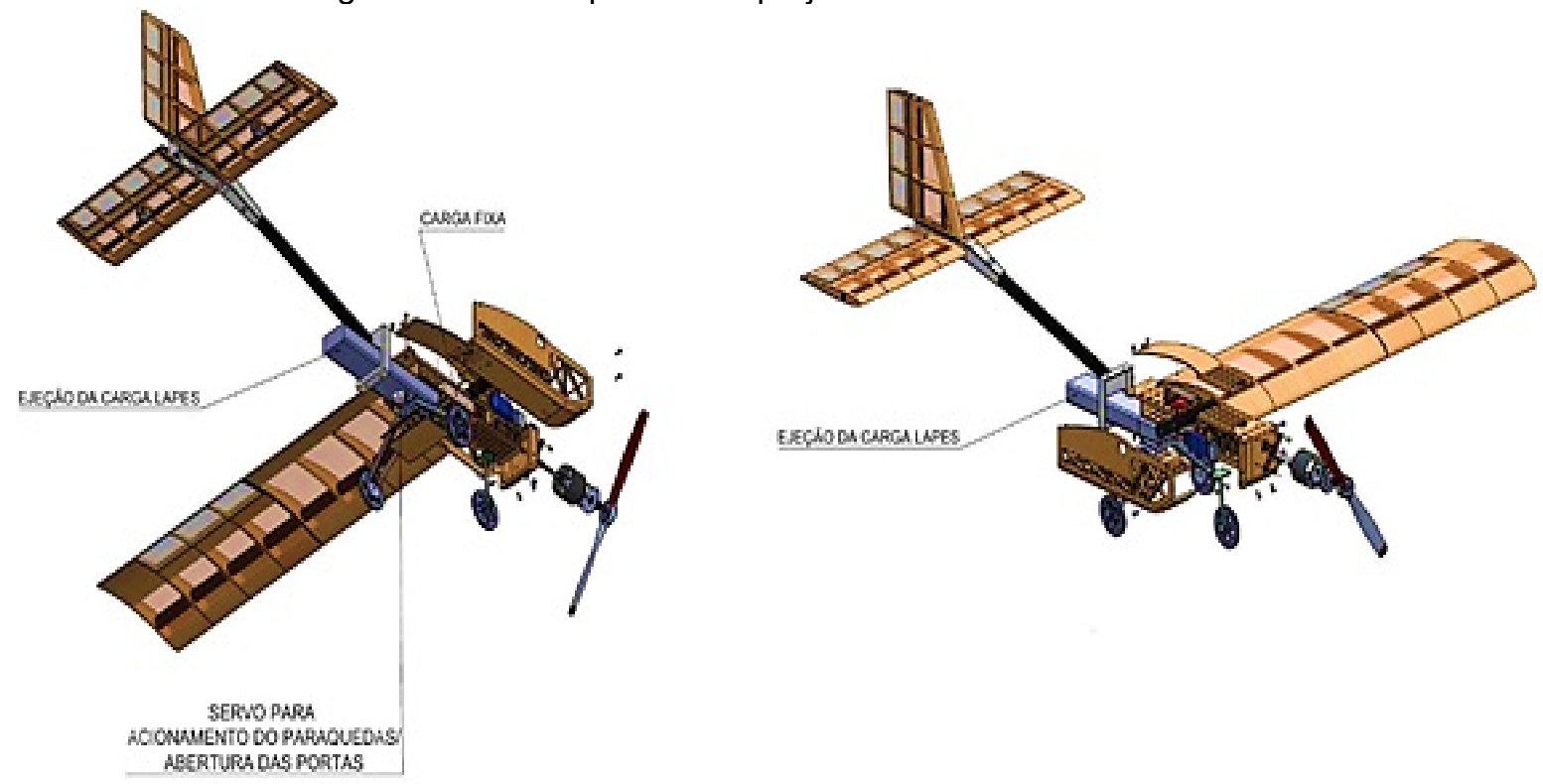

Fonte: Autor.

O desenvolvimento de um avião é um desafio enorme para os alunos de graduação, os quais se deparam com problemas e tomadas de decisões vitais para o projeto. Preparando-os para a vida profissional, além de agregar conhecimentos em diversas áreas para os estudantes da universidade por se tratar de um projeto multidisciplinar e ao mesmo tempo deixar um legado para os novos integrantes e para a universidade.

Almejando uma melhor colocação na competição, o projeto está aplicando metodologias ágeis na gestão, tais como: Kanban e sprints. Assim como métodos de detecção de falhas no processo e o aprimoramento de modelos de otimização.

No primeiro semestre de 2021, o projeto promoveu um intercâmbio com o seguinte tema: " Seminário Online de Experiência entre as Equipes de Aerodesign Uirapuru (UFPA) e Griffin (UFLA). O evento ocorreu em dois dias consecutivos, com cada equipe apresentando um seminário de 3 horas, cujo objetivo era propiciar a troca de experiências, bem como a divulgação de novos conhecimentos. Pretende-se realizar mais seminários com outras equipes para ampliar a rede de comunicação dos membros.

Mediante ao questionário realizado obteve-se respostas que auxiliaram muito no melhoramento do projeto, e consequentemente dos membros e nas atividades propostas. A Figura 4 apresenta a identificação de quem respondeu ao questionário. A Figura 6 (a) demonstra que cerca de $70 \%$ das respostas são de membros da equipe, e Fig. 6 (b) apresenta o tempo de permanência na equipe. É importante apontar que os integrantes com menos de um ano na equipe ainda não saíram, mas sim entraram este ano. Um resultado positivo é que pelo menos $43 \%$ dos membros ficam até dois anos e $25 \%$ ficam até 3 anos. Outro resultado positivo foi que mais de $90 \%$ responderam que a saída da equipe foi devido a estágio, formatura, ou falta de tempo para se dedicar a equipe.

Perguntou-se também sobre as habilidades desenvolvidas durante a permanência na equipe, dentre elas: escrita, comunicação, liderança e disciplina. A Figura 7 apresenta as porcentagens e cada habilidade citada nas respostas. A habilidade mais desenvolvida no projeto é o relacionamento interpessoal, seguido pelo aprimoramento das habilidades técnicas, cumprimentos de prazos, oral, gestão e liderança. Tais habilidades são de suma importância no mercado competitivo atualmente. 
Figura 6 - Identificação das pessoas.

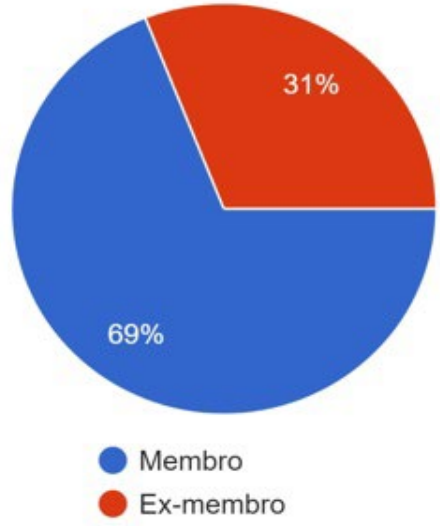

(a)

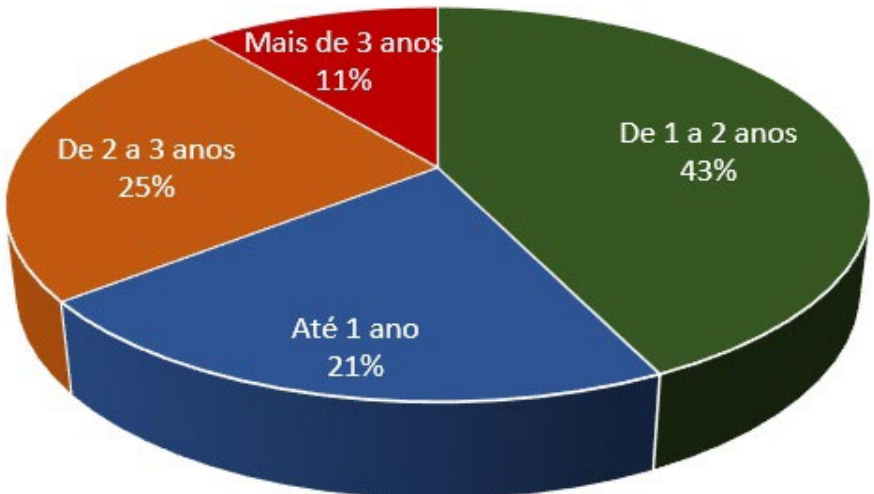

(b)

Fonte: Autor.

Figura 7 - Habilidades desenvolvidas pelos membros e ex-membros da equipe.

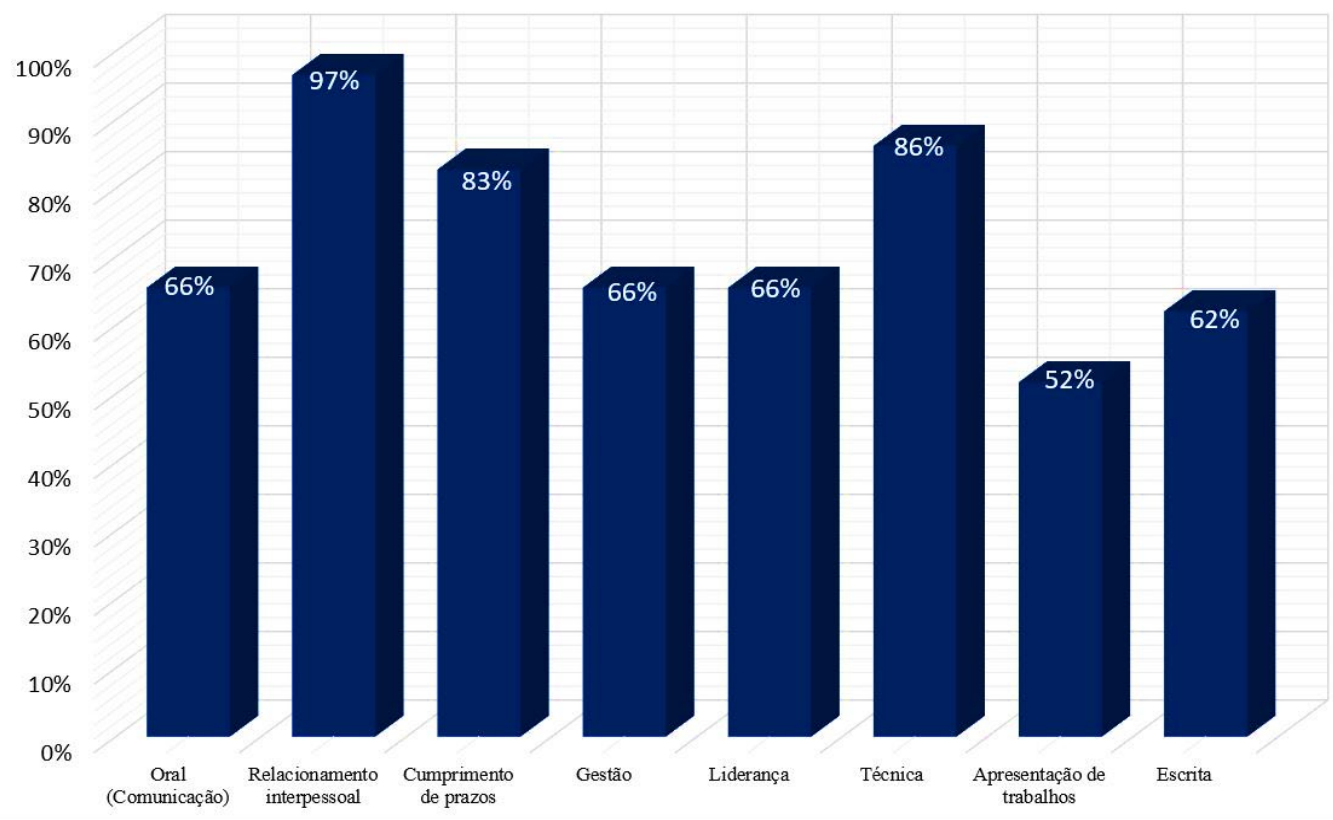

Fonte: Autor.

No questionário, todos responderam que indicariam o projeto para outros discentes, e apresentaram como o projeto acrescentou em sua vida pessoal e profissional. Relatos tais como: é interessante e motivante conseguir aplicar conceitos aprendidos na sala de aula, o relacionamento com pessoas diferentes e às vezes de cursos diferentes, a chance de conhecer outros estudantes e professores nas competições e congressos, demonstram que a equipe acrescenta no crescimento pessoal dos membros e demonstram a importância dos trabalhos de pesquisa e extensão desenvolvidos no projeto. Devido ao atual cenário muitos membros da equipe relataram a falta de encontros presenciais, 0 próprio desenvolvimento do avião assim como as atividades com a comunidade, mas os quais serão sanados quando as atividades presenciais retornarem. 
Mediante a metodologia e os resultados apresentados, o presente artigo demonstra como projetos de extensão contribuem para o plano pedagógico do curso de engenharia mecânica, e ao mesmo tempo estreita o relacionamento da universidade com a comunidade.

\section{Agradecimentos}

Ao apoio de uma bolsa auxílio pela Proex da UFPA, pelo Edital Navega Saberes de 2020. As empresas pelas licenças dos softwares SolidWorks ${ }^{\circledR}$ e Ansys ${ }^{\circledR}$.

\section{REFERÊNCIAS}

EDER S. Estudo das práticas de gerenciamento de projetos voltadas para desenvolvimento de produtos inovadores. Guia Básico de MS Project,1 ed., 2017.

ITA. Engenharia Aeronáutica. Disponível em: http://www.ita.br/aer/aer. Acesso em 10 Dez. 2019.

RAMIREZ M. A., E. Schettini, e M. Cunha. Avaliação das ações de Extensão Universitária sob a perspectiva do público-alvo: o Índice de Impacto Social, no. 2, pp. 230-244, 2017.

RAYMER. D. P. Aircraft design: a conceptual approach. AIAA Education series, 1992. ROSKAM J. Airplane Design PARTS 1-8. DA Corporation, 1985.

SAE. Regulamento SAE Brasil AeroDesign, 2020. 2020.

SAE. Programas estudantis. 2018. Disponível em: http://portal.saebrasil.org.br/programas-estudantis/saebrasil-aerodesign. Acesso em: 10 out. 2020.

MENDONÇA P., S. G. L.; SILVA, Extensão Universitária: Uma nova relação com a administração pública. 2002.

VERAS M. Gerenciamento de Projetos - Project Model Canvas (PMC). Brasport,, 1 ed., 2014. 


\title{
AERODESIGN PROJECT: A TOOL FOR DEVELOPING STUDENTS' SKILLS AND BRINGING THE UNIVERSITY AND THE COMMUNITY CLOSER TOGETHER
}

\begin{abstract}
Uirapuru Aerodesign Team is an extension project of the UFPA, created by undergraduate students of Mechanical Engineering. They are interested in multidisciplinary projects, and there are members of the mechanical and electrical engineering teams. In the project, the knowledge in the areas of numerical modeling, finite elements, technical design, aerodynamics, mechanical vibrations, the strength of materials, material selection, mechatronics, performance analysis, and structural design is applied. The objective of the team is to elaborate and execute the design of aircraft to participate in national competitions, improving and developing important skills for an engineer. The purpose of the project is to expand the students' knowledge beyond the classroom, integrate between the university and the community, and other institutions. The project also develops several important skills for professional growth, such as the elaboration of seminars, projects, budgets, and group work. This paper aims to present how the reconciled research and extension projects enhance the students' personal and professional growth, and at the same time bring the community closer to the university. During the project, we observed the growth of the members, the improvement of skills, and the interest of all of them in performing activities directed to the community as well. In the actual scenario, these activities were carried out online. The objectives were achieved by the project, developing the airplane project and at the same time taking knowledge to the community through YouTube, with an average of 250 views on the videos and the participation of external members in the mini-courses.
\end{abstract}

Keywords: Aerodesign. Multidisciplinary Project. Engineering. 